\title{
En respuesta al Editorial del Dr. Pérez Pino
}

\author{
Dr. Edgardo Escobar
}

Recibido el 3 de junio 2009. Aceptado el 10 de junio de 2009

Rev Chil Cardiol 2009; 28: 257

Estimado Sr.Editor:

Por la presente quiero agradecer el Editorial del Dr. Pérez Pino sobre ECG por Telemedicina, el que comparto en todas sus partes.

El Dr Pérez tiene toda la razón cuando dice que falta conocer el impacto clínico que ha tenido el diagnóstico precoz del Infarto Agudo del Miocardio (IAM) por Telemedicina y, por supuesto, conocer el porcentaje de pacientes que fueron sometidos a reperfusión aguda y la mortalidad en cada uno de los grupos. Estos problemas fueron debidamente señalados en las secciones de Discusión y en las limitaciones del estudio.

La responsabilidad de la Telemedicina es solamente el informe electrocardiográfico y el apoyo telefónico al médico tratante, pero no tiene ingerencia en las decisiones terapéuticas que son tomadas por el médico tratante, quien debiera seguir el protocolo diseñado por el MINSAL. Por lo tanto, tampoco tenemos posibilidad de conocer los tiempos transcurridos entre la iniciación de los síntomas y el inicio de la reperfusión.

Esto está bajo la responsabilidad del MINSAL. En coincidencia con la Ley Auge en el tratamiento del Infarto, ha habido disminución de la mortalidad del Infarto (ref 11, de Campos y cols.) y como parte del protocolo está el ECG por Telemedicina, que sin duda contribuyó al diagnóstico precoz del IAM.

Nota editorial: En el artículo al que hace alusión el Dr. Edgardo Escobar en esta editorial, están alteradas las referencias 3 y 4 .

Correspondencia: Dr. Edgardo Escobar

Callao 3341 - Santiago

Fax 4374943

Correo Electrónico: e.escobar@itms.cl 